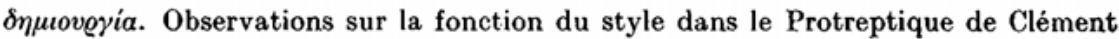
d'Alexandrie, Nymwegen 1967 (Graecitas Christianorum Primaeva 3), XXIV, 174.

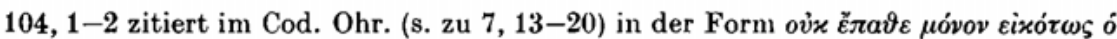

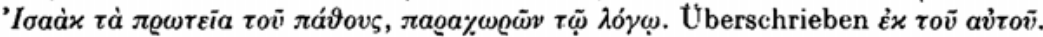

173, 14ff. vgl. Tardieu 245.

186, 12f. Zitat aus den Apokryphon des Ezechiel? (Denis, Introduction, 189f.).

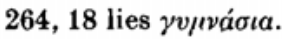

278, 31 vgl. Plut. Quaest. conviv. 7, 8, 4 (Hinweis von W.Weismann, Kirche und Schauspiele, IVürzburg 1972, 73, Anm. 21).

\title{
LITERATUR UND ADDENDA ZU BAND II
}

F. Bolgiani, La polemica di Clemente Alessandrino contro gli gnostici libertini nel III libro degli Stromati, Studi e materiali di storia delle religioni 38, 1967, 86-136.

C. Del Grande, Brevi note al testo del primo Stromate di Clemente Alessandrino, Rivista indo-greco-italica $18,1934,152-158$.

A. Hirner, Die Stromata des Clemens von Alexandrien, Paradigma für die mediale Bedeutung der Philosophie zur Entfaltung christlicher Lehre. Ein Beitrag zum Diastasenproblem, Diss. Innsbruck 1970 (Maschinenschrift).

G. Lazzati, Aevum 9, 1935, 565-569.

G. Lazzati, Introduzione allo studio di Clemente Alessandrino, Milano 1939 (darin S. 73-92: Note critiche).

A. Méhat, Remarques sur quelques passages du Ile Stromate de Clément d'Alexandrie, Revue des études grecques $69,1956,41-49$.

A. Méhat, L'hypothèse des Testimonia à l'épreuve des Stromates. Remarques sur les citations de l'Ancien Testament chez Clément d'Alexandrie, in: La Bible et les Pères, Colloque de Strasbourg 1969, Strasbourg-Paris 1971, 229-242.

A. Méhat, Clément d'Alexandrie et le sens de l'Écriture, Ier Stromate, 176, 1 et 179, 3, in: Epektasis, Mélanges Jean Daniélou, Paris 1972, 35j-365.

P. Nautin, Notes sur le Stromate I de Clément d'Alexandrie, Revue d'histoire ecclésiastique 47, 1952, 618-631. 641.

P. Nautin, Notes eritiques sur le Stromate Il de Clément d'Alexandrie, Revue d'histoire ecclésiastique $49,1954,835-841$. 887-890.

H.-R. Schwyzer, (inomon 37, 1965, 484-490 (Rez. zu Band II).

$3 \mathrm{ff}$. Dazu M. F. Osborne, Teaching and writing in the first chapter of the Stromateis of Clement of Alexandria, Journal of Theological Studies N. S. 10, 1959, 335-343.

13, 17 vgl. Philo, de migr. Abr. 15; auch Min. Fel. 27, 2. 
41,16 vgl. auch Herodot 8, 57.

71, 28-72, 5 Eupolemos 26 (B. Z. Wacholder, Eupolemos, New York 1974 [Monographs of the Hebrew Union College 3]).

80, 23-29 Eupolemos 2.

87, 25-88, 6 Eupolemos 5, nicht aus Alexander Polyhistor (Wacholder S. 6, 25).

95, 20-96, 3 Eupolemos 1.

108, 24-30 vgl. Hipp. Ref. 9, 30, 1-4, p. 263; Euseb. PE 10, 1, 1, p. 6; H. de Lubac, Exégèse médiévale 1 1, Paris 1959, 171-177.

108, 28 в̈лолгвía vgl. Orig. Komm. zum Hohenlied Vorw. p. 75, 8, korrigiert von J. Kirchmeyer, Origène, Commentaire sur le Cantique, prol., Studia Patristica X, Berlin 1970 (TU 107), 230-235.

116, 22 vgl. Tardieu (s. zu I 68, 19f.) 241-247.

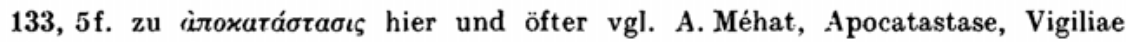
Christianae 10, 1956, 196-214.

147, 16f. Menander Mıбov́ $\mu \varepsilon v o \varsigma$ Fr. 3, 1 Koerte. Dazu U. Treu, Neues Licht auf die Vorfabel von Menanders 'Misumenos'?, Zeitschrift für Papyrologie und Epigraphik 14, 1974, 175-177.

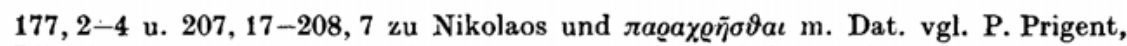
L'hérésie asiate et l'église confessante de l'A pocalypse à Ignace, Vigiliae Christianae $31,1977,13$.

212, 26 f. statt Me lies Mkk

224, 2 Гévvo Hesych

266 setze $^{*}$ vor die Anmerkungen

284, 5-285, 8 vgl. P. Nautin, Les fragments de Basilide sur la souffrance et leur interprétation par Clément, Mélanges H.-C. Puech, Paris 1974, 393-403.

287, 9-288, 7 vgl. A. Orbe, Los hombres y el creador según una homilia de Valentín, Gregorianum 55, 1974, 5-48. 339-368.

287f. vgl. K. N. Booth, 'Deficiency': A gnostic technical term, Studia Patristica XIV, Berlin 1976 (TU 117), 192-193.

331, 20-22 vgl. J. Lallot - H. Wismann, Le jugement cassé (Héraclite, fragment 28 D.-K.), Revue de Philologie 48, 1974, 65-70.

344, 19 zu Eurysos vgl. W. Burkert, Die geistesgeschichtliche Einordnung einiger Pseudopythagorica, in: Pseudepigrapha I, Vandœuvres-Genève 1972 (Fondation Hardt, Entretiens sur l'antiquité classique 18), 23-55, hier 52.

346, 14-18 nach V. Iliescu, La problème des rapports scytho-byzantins du IVe siècle av. n. è., Historia 20, 1971, 172-185, ist nicht Byzanz gemeint, sondern die im Gebiet des Atoias gelegene Stadt Bizone. 
355, 16-29 zu Anacharsis vgl. A. MacC. Armstrong, Anacharsis the 'Scythian, Greece and Rome 17, 1948, 18-23.

364, 24-27 vgl. Tardieu 241-247.

365, 7 f. vgl. Tardieu 242, Anm. 9.

372, 3-6 vgl. Q. Cataudella, Citazioni bacchilidee in Clemente Alessandrino, Studi in onore di M. Pellegrino, Torino 1975, 119-125.

274, 5 ff. vgl. C. W. Macleod, A note on P. Oxy. 3010, 29, Zeitschrift für Papyrologie und Epigraphik 15, 1974, 158-161.

396 setze * vor die Anmerkungen.

398, 18f. vgl. E. Benz, Christus und Sokrates in der alten Kirche. Ein Beitrag zum altkirchlichen Verständnis des Märtyrers und des Martyriums, Zeitschrift f. d. neutest. Wissenschaft 43, 1950/51, 195-224.

400, 8-10 vgl. Cataudella, wie 372, 3-6.

402, 20 ff. vgl. M. Hengel, Anonymität, Pseudepigraphie und ,Literarische Fälschung " in der jüdisch-hellenistischen Literatur, in: Pseudepigrapha I (wie zu 344, 19), 229-308, hier $295 \mathrm{f}$.

410, 22 ff. vgl. Hengel 293.

426, $8 \Pi 235$.

426, 10 f. Eurip. Erechtheus Fr. 367.

426, 13 Archilochos Fr. 41 Diehl.

433, 22-24 vgl. Cataudella, wie 372, 3-6.

435, $21 \mathrm{zu}$ à $\mu \circ \iota ß \eta \dot{~ v g l . ~ M . ~ M a r c o v i c h, ~ O r p h i c ~ f r a g m e n t ~} 226 \mathrm{Kern}$, Rheinisches Museum 116, 1973, 359f.

440, 12 vgl. Plot. Enn. 5, 1, 87 und V. Cilento, Parmenide in Plotino, Giornale critico della filosofia italiana 43, 1964, 194-203.

446, 26f. Stählin in seiner Ubersetzung in der Bibliothek der Kirchenväter faßt die Schrift über die Engel als Teil der defekten Stromata auf. Eine selbständige Engel-Schrift hält für wahrscheinlich R. Riedinger, Eine Paraphrase des EngelTraktates von Klemens von Alexandreia in den Erotapokriseis des Pseudo-Kaisarios?, Zeitschrift für Kirchengeschichte 73, 1962, 253-271.

449, 22 zu ह̌xлє $\mu \psi \iota \varsigma$ vgl. Ph. Derchain, Chronique d'Égypte 26, 1954, 269-279.

479, 24-26 vgl. Ev. Thom. Log. 7 (8), ed. J. Leipoldt, Das Evangelium nach Thomas koptisch und deutsch, Berlin 1967 (TU 101), sowie G. Quispel, New Testament Studies 5, 1958/59, 276-290.

484, 6 füge hinzu IV 299, 18, nach A. Méhat, Étude sur les „Stromates“ 464, Anm. 223. 